\title{
GOVERNANCE AND SUSTAINABILITY OF NETWORKED MFIS: CASE OF THE CAMCCUL NETWORK IN CAMEROON
}

\section{Nguenbu Telesphore and Nzongang Joseph}

${ }^{1}$ University of Dschang, (Cameroon), Faculty of Economics and Management, PhD, P.O Box

110 Dschang, Cameroon, Tel (+237) 677291435 / 699102109

Email teles4nguembu@yahoo.fr

${ }^{2}$ Full Professor, University of Dschang (Cameroon), Faculty of Economics and Management, P.O Box 110 Dschang, Cameroon, Tel (+237) 670330070 / 699980190

Email Jonzongang@gmail.com

Cite this article:

Nguenbu T., Nzongang J. (2021), Governance And Sustainability of Networked MFIs: Case of the CamCCul Network in Cameroon.

African Journal of Economics and Sustainable Development 4(3), 141-155. DOI: 10.52589/AJESDDIP3KYWZ

\section{Manuscript History}

Received: 28 Oct 2021

Accepted: 29 Nov 2021

Published: 17 Dec 2021

Copyright $\left({ }^{\circ} 2020\right.$ The Author(s). This is an Open Access article distributed under the terms of Creative Commons AttributionNonCommercial-NoDerivatives 4.0 International (CC BY-NC-ND 4.0 ), which permits anyone to share, use, reproduce and redistribute in any medium, provided the original author and source are credited.
ABSTRACT: The objective of this study is to determine the effect of internal and external governance mechanisms on the sustainability of the microfinance institutions of the CamCCul network in Cameroon. The study is conducted on a sample of 34 MFIs of the network over the 7-year period from 2009 to 2015. The results show, on the one hand, that the MFI's adherence to the network's Risk Management program significantly and positively affects the financial sustainability of MIFs measured by their operational self-sufficiency. On the other hand, we find that the ownership of UBC Bank shares by the MFI and the culture of the zone of activity positively and significantly affect the MIFs social sustainability measured by the number of active borrowers.

KEYWORDS: Governance, Sustainability, Microfinance Institution 


\section{INTRODUCTION}

The issue of sustainability of microfinance institutions (MFIs) has become a major concern for the future of microfinance in Cameroon. In fact, the sector is currently marked by a deep crisis that shatters its growth. This crisis is materialized by the withdrawal of accreditations and increasing closure of MIFs. In the 10 years between 2000 and 2010 more than 200 microfinance institutions went bankrupt (MINFI 2012) although the number of people attached to the services of this sector increased considerably.

The Cameroon Cooperative Credit Union League (CamCCul) network is one of the first savings and loans cooperatives in Central Africa. CamCCul was born in Cameroon's anglophone region, in Bamenda in the North West region of the country in 1963 through the technical support of Dutch and American volunteers through the Dutch Voluntary Service and the Peace Corps respectively (FOKO 1998). It then spread to the French speaking part of the country from 1974. CamCCUL is currently established in all 10 regions of the country and is the largest microfinance institution in the country and probably in Central Africa.

However, the Camccul network also witnesses bankruptcies and closures that hit MFIs in Cameroon. In fact, as part of the cleansing process of the national MFI file, the Cameroon Ministry of Finance published a list of MFIs authorised to operate in Cameroon in 2017 in which 58 MFIs belonging to CamCCul network are absent.

In this context of untimely closure of MFIs, the question of the sustainability of MFIs in Cameroon is of particular importance in ensuring the achievements of the sector ${ }^{1}$ and the development of efficient and sustainable MFIs capable of supporting development activities. Hence the current challenge for most MFIs is that of institutionalization and sustainability. Sustainability refers to the ability of an MFI to survive or to maintain a growth rhythm in the long run.

To achieve sustainability, priority was first given to financial viability and the legal status of MFIs. But with the recent crises in some MFIs we realise that these elements are insufficient. Many studies have shown that governance is the Gordian knot of microfinance (COBAC (2007), "Microfinance Banana Skins surveys" of the CFSI ${ }^{2}$ (2008, 2009, 2011, 2012 and 2014), and Fall \& Onomo (2012)). It is therefore necessary to look for governance mechanisms in these structures that may improve or reduce the sustainability of MFIs.

The sustainability of MFIs thus appears as a major challenge for the national and international community (especially donors). In this regard Sall (2008) holds that "if the importance of MFIs is widely recognized now, the focus is actually directed on the need to ensure sustainability for them to truly fulfill their role." It is in the light of the challenges of the sustainability of microfinance institutions, the importance of the role played by governance in the crises of the sector in Cameroon and recent developments on this topic, that we invite ourselves into the debate by focusing on the topic "Governance and sustainability of networked microfinance institutions" : Case of the CamCCul network in Cameroon "

\footnotetext{
${ }^{1}$ The contribution of microfinance to the financing of the economy is about $15 \%$ of loans granted by the entire Cameroonian financial sector.

${ }^{2}$ Center for the Study of Financial Innovation
} 
To achieve our objectives, this study is structured in three parts : the first focuses on the literature review on governance and the sustainability of microfinance institutions; the second presents the methodology of the study and the third the results.

\section{THEORETICAL UNDERPINNING}

\section{Sustainability: A key objective for MFIs}

Sustainability is a cross-cutting concept that helps refine reflections on the durable performance of companies. It responds to a long-run mission. Although its application in microfinance is often reduced to its financial dimension, this concept has a more global meaning and presupposes an arbitrage between the financial and social visions. In fact, this issue caught relatively little explicit and in-depth attention, except in recent studies undertaken by Morin \& al. (1994), Collins and Porras (1995), De Geus (1997a, 1997b) and Mignon (1998,1999, 2000, 2002) who address it using several approaches. As a result, the sustainability of organizations remains a concept whose content needs to be defined. According to Morin \& al. (1994, p.81), sustainability refers to "the degree to which the organisation's growth and the stability are likely to be maintained in time." In the same manner, sustainability is achieved when the company has, in the course of its history, resisted the test of the profound changes in its environment and preserved most of its identity (De Geus, 1997a,). Sustainability can therefore be interpreted as the ability of organizations to stay alive or to maintain a growth rate in the long run. Sustainability is multi-dimensional, depending on the number of variables that are used to explain it and the interactions that exist between them. However, beyond numerous dimensions, sustainability symbolizes the main purpose of the organization. In the case of microfinance, sustainability involves offering products tailored to customer needs and the mastery of various management tools of the institution.

\section{The challenges of MFI sustainability}

If financial and technical assistance are often required in the early days of an MFI, this can not be the case forever. In fact, donors expect MFIs to fulfill their promise to cover their costs and no longer turn to them for financing. From an MEI's perspective, dependence on donors in the long run is a significant risk since their decision-making becomes very slow and their choices subject to possible internal or external policy requirements.

To serve its customers sustainably, MFIs must develop the means to ensure its own continuity, that is, become a sustainable and viable organization. This implies the ability to perform each of the five functions described in the chart below: 


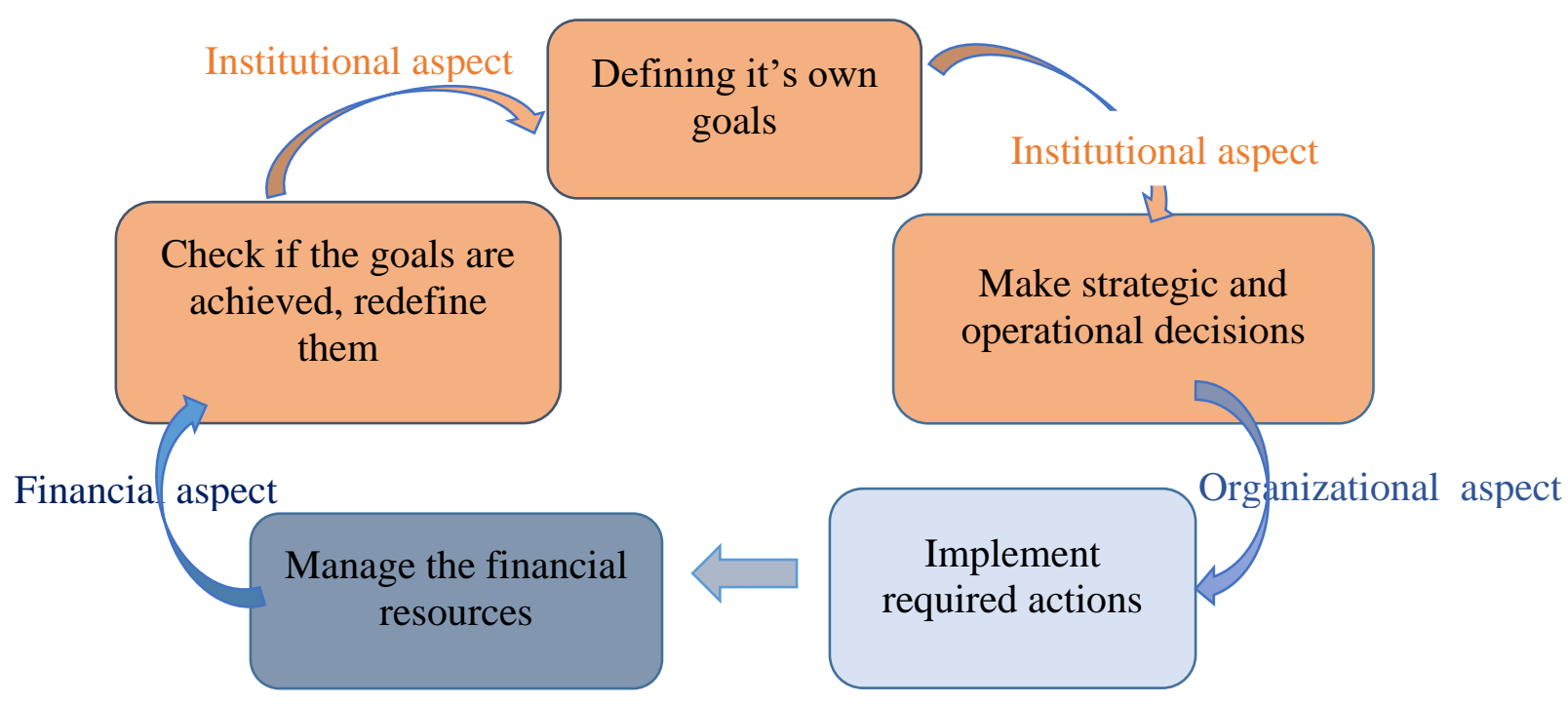

Figure 1 : Dimensions of Microfinance institutions sustainability

Source: authors

The sustainability of MFIs therefore covers three main aspects: the organizational aspect, the institutional aspect, the financial aspect and.

\section{Organizational sustainability}

Organizational sustainability is the ability of a microfinance institution to be managed locally, after the withdrawal of any external technical assistance. It requires a certain control of field operations. It also requires that the MIF may be able to develop skills and systems necessary to operate effectively. This is based primarily on the abilities of its human resources, which requires a clear separation of functions ${ }^{3}$ within the institution and the strict enforcing of codified procedures. The mastery of field operations involves the lending process, repayment follow-up and savings transactions.

An MFI is considered viable at the organizational level if it has the physical assets, processes and human resources to function efficiently, in line with its strategy. This structuring effort is a key issue in the sustainability of MFIs although experience shows that it is often overlooked. Priority is usually given to the development of financial products within the vision of a pilot project and to the growth in number of clients and the portfolio, allowing the validation of products and the achievement of financial equilibrium.

As in any organization, human resource management is a key success factor in an MFI. This consists in setting up a professional administrative management that is rigorous and responsive to staff problems. Moreover, it consists in the development within the MFI of mechanisms and a culture for the development of individuals, in terms of their abilities and commitment to the MFI.

\footnotetext{
${ }^{3}$ Management, operations, audit, human resources etc. ... 


\section{Institutional sustainability}

This can be defined as the establishment of a clear governance that defines the strategy and monitors its implementation through the adoption of an appropriate legal status. This is a structural choice, since it will direct the rules of operation of the MFIs. Internally it refers to the attribution of powers and rules of decision making that are defined by the status. Externally, it refers to the authorized activities, regulatory authorities, information disclosure requirements, applicable laws ... etc. Institutional and social autonomy within the institution is embodied in the distribution of power between employees and owners which is a key factor in the governance of the institution. It is done through the legal status ${ }^{4}$.

\section{Financial sustainability}

The financial sustainability of MFIs can be defined as the act of achieving financial balance and being able to finance growth. It reflects its ability to cover its costs through its production and to build a strong financial structure. A policy that target the financial sustainability of the MFIs should specify on three key aspects:

First and foremost, it depends on the setting of interest rates charged to customers. In fact, the institution's financial income comes primarily from the interest charged on loans granted. It is therefore essential to set a level of interest rates that enables the MFI to bear the different costs of the institution. Too low interest rates would lead to deficits. But unnecessarily high interest rates penalize customers, thus contradicting the social mission of the MFI. The MFI could therefore lose its customers to competing MFIs.

Secondly, the institution will have to obtain the necessary financing for its growth. This can come from the equity capital invested in shares (in the case of private companies), grants received and accumulated profit of previous years. They can also come from loans which are loans from banks or international lenders specialized in microfinance and savings of customers if the IMF is authorized to collect these savings.

Finally, the institution should anticipate and plan for growth. Year after year, the timely achievement of a balanced budget is often a delicate exercise for an MFI. Planning for the coming years is even more delicate and requires advanced forecasting and technical skills. But the anticipation of funding needs is even more necessary since MFIs experience structurally growth for two reasons: They often have a large market of potential borrowers; the Micro Loans granted are frequently renewed, and the amount of these loans tends to increase with an increase in the reimbursement ability of their clients.

\section{The sustainability of MFIs: A combination of financial performance and social performance}

In microfinance, sustainability depends on the institution's performance. The performance of a company can be defined as the achievement of objectives defined by the company relative to the means used to achieve them. It therefore refers to the efficiency of the company or attaining a given level of achievements defined using previously identified indicators. These objectives may be financial or social. The MFIs financial performance is based on the analysis of

\footnotetext{
${ }^{4}$ There are four main legal status for MFIs: The project statute, nonprofit association status, the status of mutual or cooperative and the company status of private capital
} 
indicators of profitability. A profitable institution is one that is able to produce enough revenue to cover its costs within a given period. This can be done through a reduction in costs and / or an increase in revenue. This reduction in cost is a challenge for the MFI because it is one of the safest and efficient ways of building self-sustaining, sustainable and efficient institutions (Bhatt and Tang, 1998). The increase in revenue is done through the achievement of a given financial margin. This margin is a positive difference between the rate at which the MFI acquires funds and the rate at which it lends to cover all direct and indirect costs associated with the activity (Labie 1996).

The social performance of MFIs seeks to explain how financial services affect the lives of the beneficiaries who are mostly the poor. It is the measure of the direct and indirect impact of microfinance activities on the lives of its beneficiaries and their surroundings in terms of their financial, economic, social and professional inclusion. In fact, many funders and individuals make available MFI funds for improving the conditions of the poors. MFIs are answerable to these donors and are required to explain to them if their goals (reducing the vulnerability of the poor, increasing their incomes, increasing in autonomy ...) have been achieved. An MFI that seeks to continue benefiting from the confidence of its donors and continue receiving funds to survive in the long run, must also try to perform well socially. That is to sustainably serve a growing number of poors and excluded, improve the quality and adequacy of services and improve the economic and social situation of the beneficiaries of its services.

Several reasons explain the link between social performance and sustainability of MFIs. In fact, it is true that the social performance of MFIs entails costs such as customer training costs and costs for the promotion of information sharing groups in view of increasing transparency. In the long-run, these costs can be reduced and result in profits for the institution. Transparency and information exchange will create a climate of trust that encourages customers to repay loans. Training and participation increase the productivity of agents and reduce transaction costs for the institution by reducing the cost of monitoring and control of financial transactions. When there is trust, it becomes possible for MFIs to make innovations in terms of products, services and customer relationships. Social performance therefore strengthens the stability and sustainability of MFIs.

\section{GOVERNANCE AND SUSTAINABILITY OF MFIS: HETEROGENEITY OF PREVIOUS RESULTS}

Some recent studies on microfinance governance focus on the identification of governance mechanisms that affect the financial and social performance of MFIs. We structure our literature review according to the internal or external nature of the mechanism.

\section{The effects of internal mechanisms on the sustainability of MFIs}

These mechanisms include: the board of directors, the status, the organizational form and regulation of microfinance institutions.

\section{The Board of Directors and sustainability of MFIs}

Andres and Vallelado (2008) find that the relationship between the size of the board and bank performance is not linear. The curve describing this relationship takes the form of an inverted $\mathrm{U}$. The threshold of 19 directors is identified as that from which the board is no longer effective as a governance mechanism. For Galbreath $\&$ al. (2008), the most viable MFIs are those that 
have a smaller board size. Regarding the composition of the board, Varun and Jaiswall (2015) show that the diversity of the board in terms of gender is significant because MFIs with high diversity of control are more efficient and have a positive effect on performance (Adams and Ferreira (2009)). According to Hartarska (2005) and Webb (2004), board directors with a greater proportion of women more easily reach the 'poorest' borrowers and are therefore more socially efficient. For Hartarska (2005), Hirisch and Brush (1994) (Rosener, 1995) the presence of women on the board improves the viability of MFIs. Furthermore, they find a positive and significant effect of the size of the Board of Directors on profitability, indicating that MFIs with large size boards are more profitable and likely to be sustainable.

\section{Legal status and sustainability of MFIs}

In their studies, Hartarska, (2005), Mersland and Strøm (2008; 2009) find that there is no significant difference between social and financial performance between NGOs and private microfinance companies. White and Campion (2002), Fernando (2004) and Ledgerwood and White (2006) on their part find that MFIs incorporated as a limited company exercise a better control of managerial discretion and are therefore more efficient than non-profit MFIs. Also, for Fischer, (2000); Desrochers and Fischer, (2005); Cuevas and Fischer, 2006), except for very few cases, all MFIs belonging to strategic networks are at least as efficient as those belonging to fragmented networks.

\section{The credit model and the sustainability of MFIs}

The credit model (group lending or individual loans) as a governance mechanism reduces conflicts arising from the credit relationship (Cuevas and Fischer 2006). Thus, according to Khandker (1998), Ghatak (1999) Armendariz de Aghion and Morduch B, (2000), Laffont and Nguessam (2000) Casar \& al (2007), group loans with collateral security are often used as a default risk minimization mechanism to improve the portfolio performance of MFIs and achieve financial viability. Hartarska (2005) finds no significant effect of the credit model on the sustainability and social efficiency of MFIs in Central and Eastern Europe. However, the least profitable MFIs are those that adopt individual credit. Mersland and Strøm (2009) find that individual credit is positively associated with high amounts of loans. They do not find a significant difference in performance (profitability and viability) between MFIs by lending methodology. Cull \& al. (2007), based on a sample of 124 MFIs, found that MFIs that provide individual loans are more profitable and sustainable.

\section{The effects of external mechanisms on the sustainability of MFIs}

According to the findings of Hartarska (2009), external governance mechanisms (regulation and financial transparency) affect neither the sustainability of MFIs nor their social efficiency. Hartarska and Nadolnyak (2007) arrive at the same conclusion regarding the relationship between supervision and the sustainability of MFIs on the one hand, and that between supervision and social efficiency on the other. Mersland and Strøm (2009) find no positive effect of supervision on profitability, sustainability and social effectiveness on a sample of 278 private microfinance companies. Cull \& al. (2009) conclude at the end of their study that the financial and social effectiveness of supervision depends on the selected estimation model (be it OLS or Heckman selection model).

It follows from the studies above that beyond the financial aspects, the sustainability of MFIs is also a governance issue. Our contribution in this study is to evaluate the effect of mainly 
external governance mechanisms that have not yet been studied in the literature by focusing on the MFIs of the CamCCul network in Cameroon. These include : cultural aspects such as establishment of the MFI in the English or French-speaking region of the country, membership of the MFI to the Network Risk Management Program and its shareholding participation in UBC Bank.

\section{METHODOLOGY OF THE STUDY}

This study aims to assess the effect of governance mechanisms on the sustainability of MFIs in Cameroon's CamCCuL network. For this, we use secondary data from the financial statements of 34 MFIs of the CamCCul network for the 7 year period from 2009 to 2015.

\section{Choice and description of the variables}

The choice of variables is done drawing inspiration from empirical studies by Mersland \& Strøm (2008), Tchakoute (2010) and Abalo (2011). Thus, in our methodology we use two types of variables, namely : dependent and independent or explanatory or exogenous variables.

\section{Dependent Variables sed to measure sustainability}

Traditionally, the sustainability of MFIs is measured by two key indicators, namely financial and social performance indicators (Lafourcade \& al., 2006. Hartarska, 2005 and 2007; Mersland and Strøm, 2008 and 2009; Cull \& al. 2007; 2009). In this study we use the following variables as financial and social indicators of sustainability of MFIs.

- Operational Self-Sufficiency (OSS): It is a first element that indicates to the institution if it is heading towards self-sufficiency. It shows the ability to cover the costs from the financial revenues only (without the help of donors), which is a sign of growing selfsufficiency (Manos and Yaron, 2009). A movement toward the threshold of 100\% selfsufficiency reveals that the institution delivers itself from reliance on donors and other sources for delivery of financial services.

- The Number of Active Borrowers (NAB) : This is the Number of people who have obtained a loan from the MFI for which there is still a balance to be paid, or who are primarily responsible for the repayment of a portion of the outstanding gross loans during the period. The more the number of active borrowers is, the more socially sustainable the MFI is, since it serves more and more poor people.

\section{Governance variables: Independent Variables}

The governance variables are grouped according to whether they are internal or external mechanisms. They include: Size of the Board, Representativity of women in the Board, Manager's gender, shareholding in UBC, Zone of establishment, Membership of the risk management program and the Age of the MFI. 
African Journal of Economics and Sustainable Development

ISSN: 2689-5080

Volume 4, Issue 3, 2021 (pp. 141-155)

www.abjournals.org

The table below presents the variables used in this work.

Table 2 : Table of variables used

\begin{tabular}{|c|c|c|c|c|}
\hline Variables & $(A)^{5}$ & \multicolumn{2}{|c|}{$(B)^{6}$} & Définitions \\
\hline \multicolumn{5}{|c|}{ Dependent variables (sustainability variables) } \\
\hline $\begin{array}{l}\text { Operational Self- } \\
\text { Sufficiency }\end{array}$ & OSS & & & $\begin{array}{l}\text { The ability to finance the costs from the financial } \\
\text { income }\end{array}$ \\
\hline $\begin{array}{l}\text { Number of Active } \\
\text { Borrowers }\end{array}$ & NAB & & & $\begin{array}{l}\text { Number of people who have obtained a loan } \\
\text { from the MFI for which there is still a balance to } \\
\text { be paid. }\end{array}$ \\
\hline \multicolumn{5}{|c|}{ Independent variables (governance variables) } \\
\hline \multicolumn{5}{|c|}{ internal governance mechanisms } \\
\hline Size of the Board & TCA & $+^{7}$ & $+^{8}$ & $\begin{array}{l}\text { The number of members on the Board of } \\
\text { Directors of the IMF }\end{array}$ \\
\hline $\begin{array}{l}\text { Representativity } \\
\text { of women in the } \\
\text { Board }\end{array}$ & FECA & + & + & $\begin{array}{l}\text { Proportion of women in the total number of } \\
\text { directors }\end{array}$ \\
\hline $\begin{array}{l}\text { Manager's } \\
\text { Gender }\end{array}$ & FEDI & + & + & $\begin{array}{l}\text { dichotomous variable which takes the values } 1 \text { if } \\
\text { the MFI is directed by a woman and } 0 \text { if the MFI } \\
\text { is directed by a Man. }\end{array}$ \\
\hline \multicolumn{5}{|c|}{ External governance mechanisms } \\
\hline $\begin{array}{l}\text { Shareholding in } \\
\text { UBC Bank }\end{array}$ & AUBC & - & + & 1 if the MFI is a UBC shareholder o ; otherwise \\
\hline $\begin{array}{l}\text { Zone of } \\
\text { implantation }\end{array}$ & ZI & + & + & $\begin{array}{l}1 \text { if the MFI operates in Anglophone zone and } 0 \\
\text { if } 149 \text { te volves in Francophone zone }\end{array}$ \\
\hline $\begin{array}{l}\text { Membership to } \\
\text { the risk } \\
\text { management } \\
\text { program }\end{array}$ & PROGERI & + & + & $\begin{array}{l}1 \text { if the MFI is registered in the risk management } \\
\text { program, otherwise } 0\end{array}$ \\
\hline Age & AGE & + & + & Number of years of life of the MFI \\
\hline
\end{tabular}

Source : Authors

\footnotetext{
${ }^{5}$ Acronym

${ }^{6}$ Predicting sign

${ }^{7}$ OSS

${ }^{8} \mathrm{ROA}$
} 


\section{Empirical Model}

To highlight the effect of MFI governance mechanisms on their sustainability, we use two models borrowed from Woller (2003) which are written as follows:

DOSSAit $=a_{0}+a_{1}$ FEDIit $+a_{2}$ TCAit $+a_{3}$ REFECAit $+a_{4}$ AUBCit $+a_{5}$ ZIit $+a_{6}+a_{6}$ PROGERIit $+a_{7} A G E i t+\varepsilon i t$

$$
\begin{aligned}
& \triangle N A B i t=a_{0}+a_{1} \text { FEDIit }+a_{2} \text { TCAit }+a_{3} \text { REFECAit }+a_{4} A U B C i t+a_{5} \text { ZIit }+a_{6}+a_{6} \text { PROGERIit } \\
& +a_{7} A G E i t+\varepsilon i t
\end{aligned}
$$

These are in fact panel models that use two indices $i$ for individual and $t$ for time. Unlike time series models that help in studying the evolution of phenomena in time without any control of the heterogeneity among individuals, the panel model has the advantage that it can analyze the heterogeneity between individuals while taking into account the dynamic behavior. It therefore simultaneously studies the two sources of statistical information variation: The intraindividual variability and inter-individual variability.

\section{RESULTS AND DISCUSSION}

Prior to the study of effects of Operational Self-Sufficiency, Number of Active Borrowers (NAB) and the different explanatory variables, it is necessary to check if the links between the variables are not too strong or unbalanced (for example, two highly correlated variables and other quasi-independent). The following table shows the matrix of correlation coefficients.

Table 3 : Table of correlation between variables

I NAB OSS FEDI TCA REFECA AUBC ZI PROGERI Age

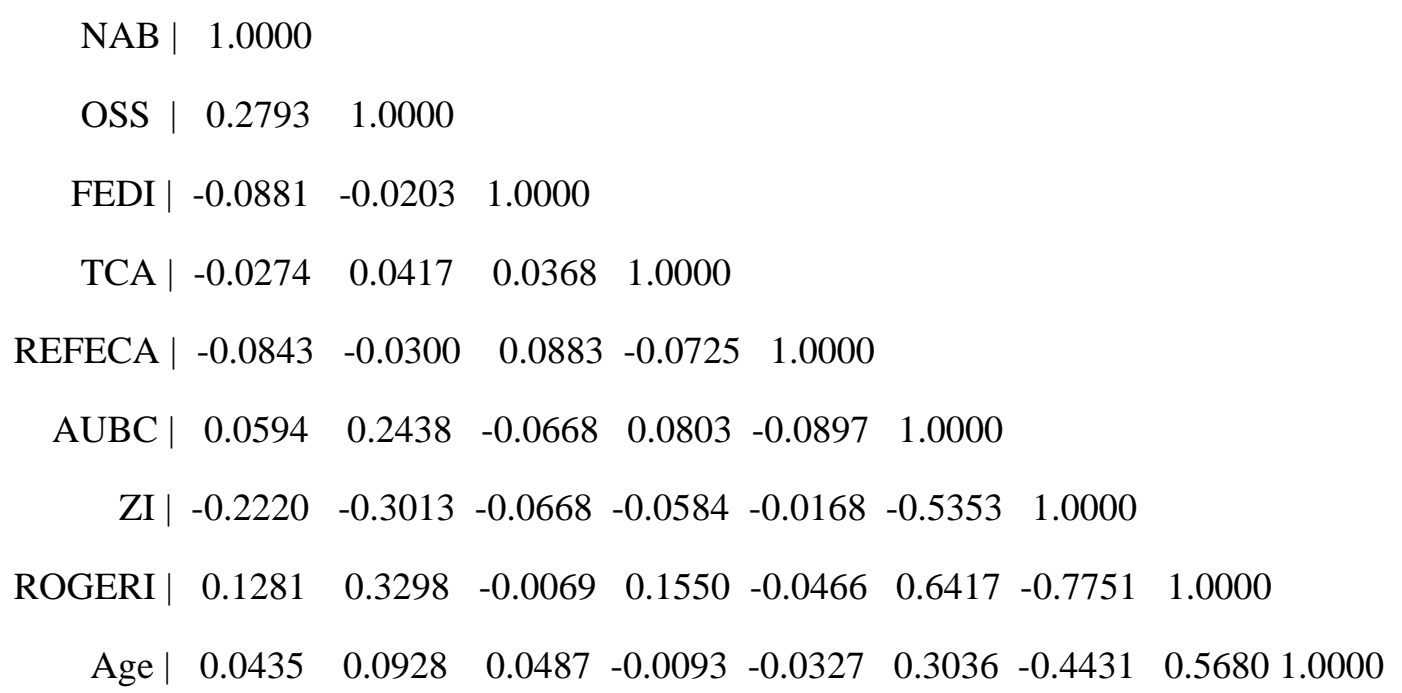

From the analysis of this table, it appears that the NAB is positively and significantly correlated with shareholding in UBC Bank (AUBC) and the age of the MFI. This positive correlation with the AUBC is expected since shareholding at UBC causes additional income in case of positive 
results of the bank for the shareholder MFIs. Also, concerning the variable "AGE", the greater the age of the MFI, the more it has the mastery of operations and it gains market share. This leads to a significant positive correlation with NAB. The NAB is negatively and significantly correlated with the size of the board, and the presence of women at the head of the institution. Concerning the OSS, it is positively and significantly correlated with the size of the board and the age of the MFI. However, the representation of women in management and the board are negatively and significantly correlated with the OSS.

Also, the positive and negative correlations between the independent variables taken in pairs are low. We can thus say that there are no collinear phenomena between the different variables.

\section{Effect of governance mechanisms on operational self-sufficiency}

The estimation of Model (1) is done through the Generalized Least Squares with random effects method going from the results of preliminary and specification tests. We obtain the results shown in the following table:

Table 4 : Result of Model (1) estimation

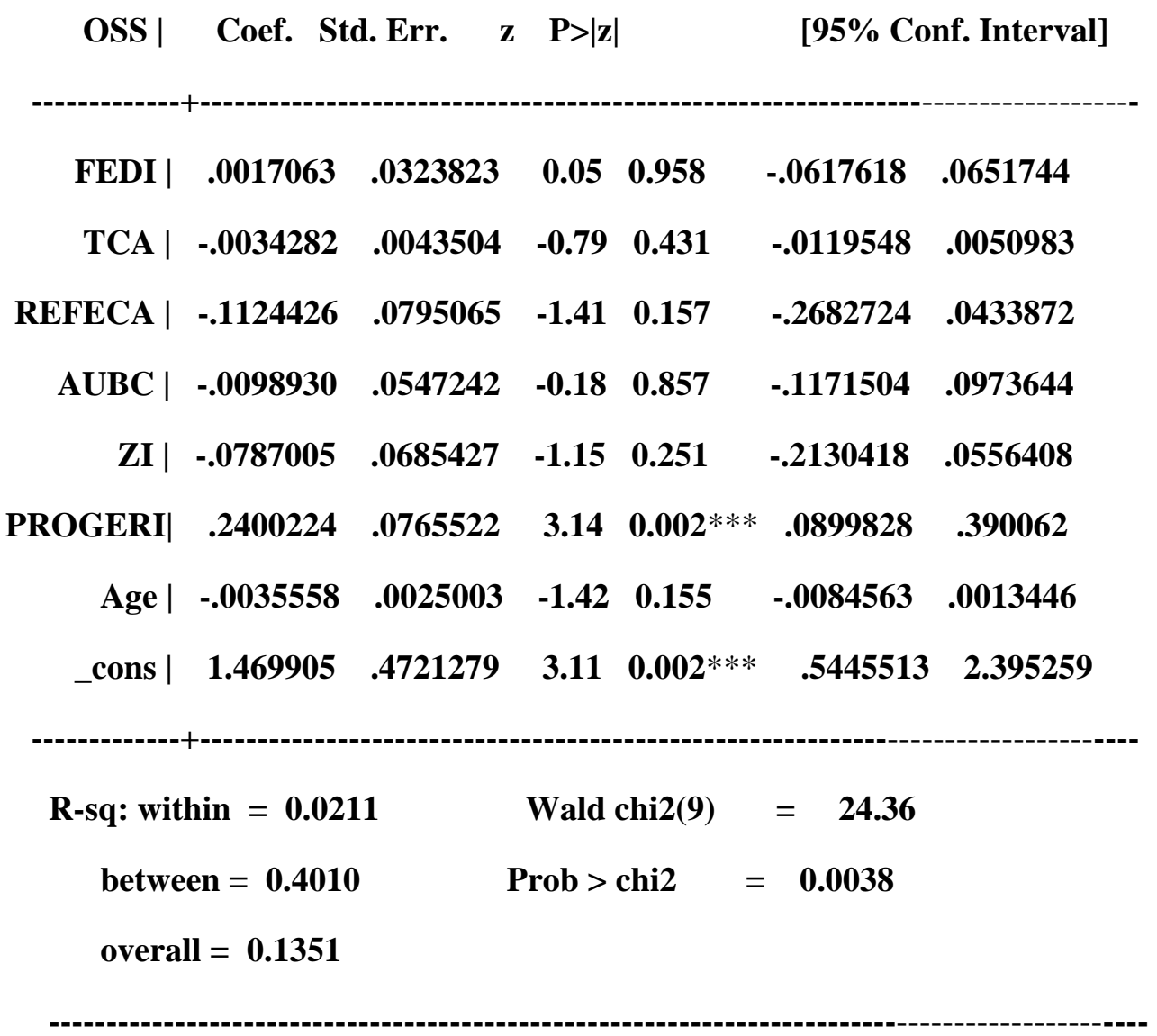

*** Significance at the $1 \%$ level;

Source : Authors

The analysis of the above regression's table shows that the governance variable PROGERI, that is the adherence of MFI to the risk management program affects significantly and 
positively the MFI's OSS at the threshold of 1\%. This reflects the fact that adhesion to the risk management program helps MFIs in minimizing financial losses because it provides some additional guarantee on loans granted to customers. In fact, the risk management program is a support program that helps MFIs facing financial difficulties. It is a kind of insurance for MFIs, that aims to reduce their probability for loss and then increase their ability to generate enough revenue to cover their expenses. The result shows that the MIF's adherence for this program increased his OSS by $24 \%$. Another variable that affects positively but not significantly the OSS is FEDI that is the MFI's management by a female gender. In fact, the result shows that the fact of having a woman at the head of MFI increases his OSS by about 1,7\%. Other variables such as Board size, REFECA that is Representativity of women in the Board, ZI ( implantation of the MFI in the Anglophone region) and AGE negatively affect MFI's OSS. This result concerning AGE could be explained by the fact that the profitability of an MFI is threatened as its age increases. In fact, the progression of the MFI towards maturity necessarily leads to increased tax, operating and staff expenses that require significant additional financial resources to be covered. Also, the maturity of the MFI is linked to that of the sector which is also reflected by the entry into the market of other MFIs which leads to an increasingly fierce competition in the market and to a decline in growth of market shares and therefore profitability.

\section{Effects of governance mechanisms on the Number of Active Borrowers}

The estimation results of our second regression model also by Generalized least squares with random effect gives us the following results:

Table 5 : Result of Model (2) estimation

NAB $\mid$ Coef. $\quad$ Std. Err. $\quad z \quad P>|z| \quad[95 \%$ Conf. Interval $]$

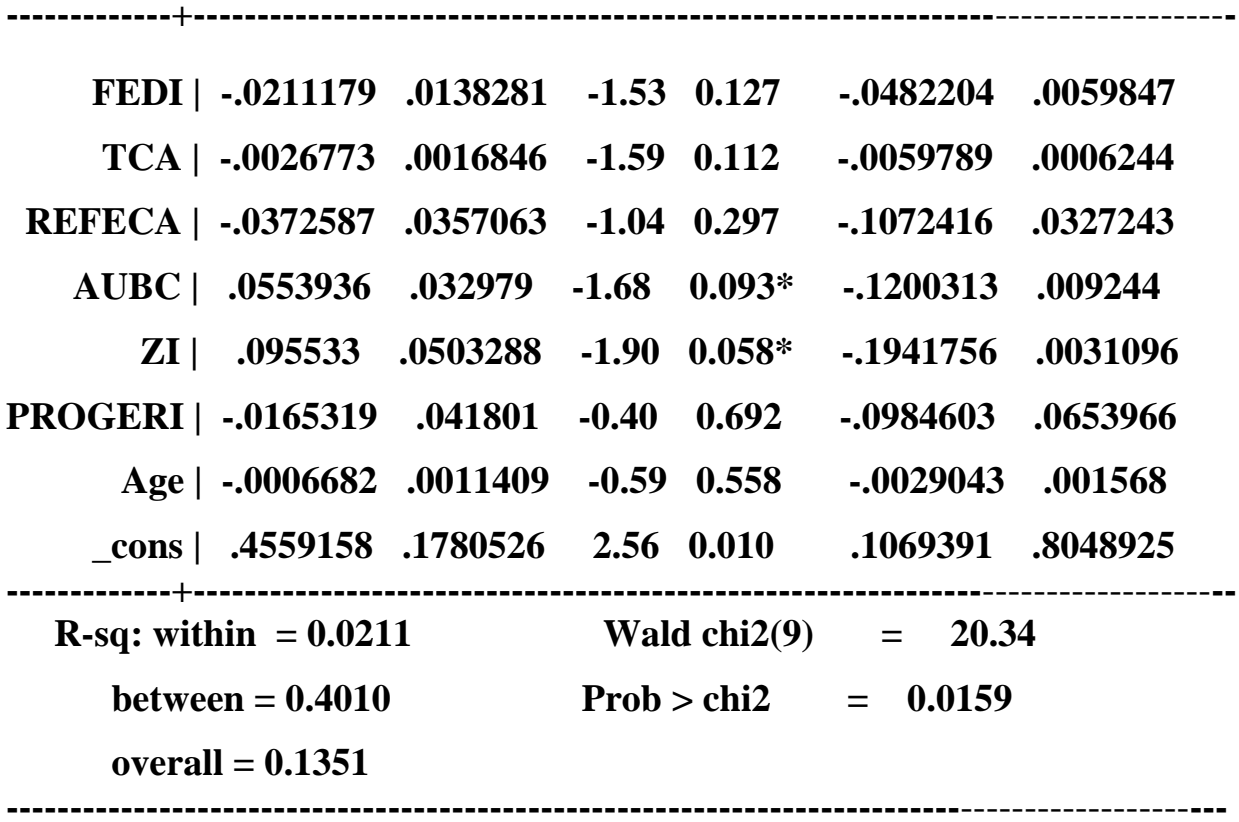

* Significance at the $10 \%$ threshold level

Source : Authors 
A look at this table reveals that the variables that significantly affect the NAB include: Shareholding at UBC Bank and the Zone of implantation (ZI) that positively affect the social performance of MFIs at the $10 \%$ level. The ZI coefficient shows that MFIs operating in the English-speaking areas of the country have policies that allow them to better reach the poorest peoples. This may also reflect the fact that the inhabitants of the English-speaking regions have a greater culture of microcredit compared to those of the French-speaking regions. This can be justified by the fact that before spreading to the French-speaking part of the country in the years 1990, microfinance in its modern form was born in Cameroon Anglophone region precisely in Bamenda in 1963. The AUBC result reflects the fact that when an MFI has shares in a bank, this offers it an important financial capacity that allows it to grant loans to more people. This also gives it a certain credibility that pushes the population to demand its products and services.

Regarding other variables we can say that they affect negatively but not significantly the social sustainability of MFIs.

\section{CONCLUSION}

The purpose of this study was to determine the effect of governance mechanisms on the sustainability of CamCCul network MFIs. To achieve this, two econometric models were built. The first linking governance mechanisms (external and internal) and Operational selfsufficiency and the second, featuring these same relationships between governance mechanisms and the number of active borrowers of the CamCCul MFI's sample. Our methodology was based on the panel data generalized least squares regression using data from 34 CamCCul network MFIs operating in Cameroon during the 7 years period from 2009 to 2015 .

Globally, the results show that the variables that significantly affect the sustainability of the MFIs of the camccul network are PROGERI, AUBC and ZI. This means that the MFIs' adherence to the network's risk management project, the MFI's detention of UCB bank shares and the fact that MFIs operate in the country's English-speaking areas are mechanisms that can guarantee the financial and social performance of the MFIs of the network camccul and thus their sustainability. This is why we recommend that the MFIs in the network who have not yet joined the Risk Management Project do so in order to minimize the risks associated with their activities. We also recommend MFIs that have the means to purchase UBC bank shares to do so. This can help them not only to increase their income, but also to diversify their portfolios. 


\section{REFERENCES}

ABALO K, (2011), Pérennité et succès des Institutions de Microfinance au Togo African Economic Research Consortium (AERC),

Armendáriz, B and Morduch J. (2000), The Economics of Microfinance, the MIT Press

Bhatt et Tang (1998) «Determinants of Repayment in Microcredit:Evidence from Programs in the United States » International Journal of Urban and Regional Research Volume 26.2 june 2002 360-76

Andres and Vallelado (2012), Board Determinants in Banking Industry : An International Perspective Managerial and decision economics, Econ. 33: 147-158 (2012) Published online 9 January in Wiley Online Library

Campion, A. (2002), Current governance practices of microfinance institutions, The Microfinance Network Occasional Paper 3, Washington, D.C.

COBAC (2000), Situation des institutions de microfinance du Cameroun, Yaoundé.

Cull. R., Demirguç-Kunt A., Morduch J. (2007), Financial performance and outreach: a global analysis of leading microbanks, The Economic Journal, vol. 117, pp. 107-133.

DE Geus A. (1997 a), La pérennité des entreprises, expériences des entreprises centenaires au profit au profit de celles qui veulent le devenir, Edition Maxima Laurent du Mesnil, Paris, $268 \mathrm{p}$.

DE Geus A. (1997 b): The Living Company: Habits for Survival in a Turbulent Business Environment, Harvard Business Press, 215p.

Fall, F, S, Onomo, C, 2012, Microfinance au Cameroun : entre crise de gouvernance, crise de crédit et crise de régulation, Revue Techniques Financières et Développement, No 126, Mars.

FOKO E. (1998), Le système d'épargne rural : Analyse du fonctionnement et des performances dans l'ouest du Cameroun, Thèse de Doctorat, Université Lumière, Lyon 2, P 201

Hartarska V., (2005), Governance and Performance of Microfinance Institutions in Central Eastern Europe and the Newly Independent States, World Development, vol. 33, $\mathrm{n}^{\circ} 10$,

Hartarska V. \& Nadolnyak D., (2008), Does rating help microfinance institutions raise funds? Cross-country evidence, International Review of Economics and Finance, vol. 17, $\mathrm{N}^{\circ} 4$, pp. $558-571$.

Hartarska V., (2009), The impact of outside control in microfinance, Managerial Finance, Vol. 35, $\mathrm{n}^{\circ} 12$,

Labie (1996), Perspective d'autonomie et de pérennisation des systèmes financiers, Revue tiers monde, Tome XXXVII, no 145, Janvier- Mars.

Labie M. \& Mersland R. (2002), Corporate Governance Challenges in Microfinance Publish in The Handbook of Microfinance

Lafourcade \& al. (2005), Overview of the Outreach and Financial Performance of Microfinance Institutions in Africa, Microfinance eXchange Information, April, $20 \mathrm{p}$.

Mersland R. \& Strom R. O. (2007): Performance and Corporate Governance in Microfinance Institutions, MPRA Working paper, $\mathrm{n}^{\circ} 3888$, Agder University, Norway, June, Online at http://mpra.ub.uni-muenchen.de/3888/, 37p

Mersland R. \& Strøm R. Ø., (2008), Performance and Trade-Offs In Microfinance Institutions- Does Ownership Matter? Journal of International Development, vol. 20, $n^{\circ} 5$, 
Mersland R. \& Strøm R. Ø., (2009), Performance and Governance in Microfinance Institutions, Journal of Banking and Finance, vol 33, $\mathrm{n}^{\circ} 4$

Mignon S. (1998), Une approche de la perennité de l'entreprise, Revue française de gestion 2009/2 ( $n^{\circ}$ 192); Ed Lavoisier

Mignon S. (2001), Stratégie de pérennité d'entreprise, Édition. Paris Vuibert DL, cop. Collection. Entreprendre 1281-5691

Morin \& al. (1994), L'éfficacité de l'organisation: conception intégrée, Edition Gaetan Morin

Onomo C. (2014) Appartenance à un réseau, gouvernance et performance dans les coopératives d'épargne et de crédit au Cameroun Consortium pour la Recherche Economique et Sociale, Serie de documents de recherche, 2014/ 67

Sall B. M. (2008), Les determinants de la viabilité financière des IMF au Sénégal

Tchakoute T.H. (2010), Forme juridique et performance des institutions de microfinance une approche comparative », Revue Africaine de l'Intégration Vol.2 (2) 